\title{
Reality, unreality, and artistic deception: the ethical dimensions of the knowledge organization of art documentation
}

By Deborah Lee, Department of Information Studies, University College London Version as submitted post review to Knowledge Organisation, with a) the addition of author information and $b$ ) removal of track changes to indicate post-review editing

\section{Abstract}

The ethics of describing and indexing works which have an element of deception is an important topic within the arena of knowledge organization (KO). However, what happens if the unreal element is for artistic purposes and is part of the experience of the document? The focus of this article is on the $\mathrm{KO}$ of art documentation. It considers art documents where unreality and mistruth are part of a document's creative and artistic purpose. Three examples of exhibition documentation for contemporary art are explored. These illuminate the KO implications of unreal elements in artworks, exhibitions and documents, and the interplay between them. Three models are then presented relating to the KO of unreality. Model 1 shows how the wishes of the creator are a significant part of ethical KO for art, and the ethical KO decisions which result from the performative and experiential aspects of art documentation. Model 2 illustrates how the placement of the unreality in relation to metadata creation can have a critical impact on ethical decisions in KO. Model 3 posits unreal-ness as a novel type of information about metadata creation, introducing categories such as motive for the deception. It shows how this original way of contemplating applied ethics in $\mathrm{KO}$ is vital for all ethically challenging works. Ultimately, considering the KO ethics of art documentation extends our thinking about how to deal with deception and unreality, and adds an important aesthetic-ethical dimension to the corpus of work on KO ethics. 


\subsection{Introduction}

Knowledge organization (KO) discourse about ethical responsibility shows how the act of classifying and cataloging a document has an ethical dimension (for example, Bair 2005, Shoemaker 2015, Snow 2015). An important aspect of this research has been to consider the ethics of dealing with works which are in some way deceptive. This is particularly pertinent considering the current era of misinformation, alternative facts and untruths. However, creative works frequently play with the idea of truth and reality, and these artistic untruths and unrealities may be built into the documents which accompany such creative works. This is particularly true for contemporary art, where documentation accompanying exhibitions and installations are sometimes part of the experience of the artworks. So, this article considers the ethical considerations for art documentation with elements of the unreal, and asks how such works can expand and challenge existing thinking about ethical KO.

Exhibition catalogs are, at their barest, works which document and record an exhibition including its artworks and artists (ARLIS NA 2010, Grandal Montero 2017); however, the late twentieth-century and twenty-first-century exhibition catalog will frequently include much more, such as critical essays, biographical information, general surveys of the artists' works, and analyses of the exhibited artworks (ARLIS NA 2010; Grandal Montero 2017). Typically, art exhibition catalogs are created by curators and others working on behalf of the museums or galleries responsible for the exhibition. Textual content for the catalogs is produced by the curators themselves and writers commissioned by those curators or catalog editors, which for exhibitions relating to contemporary works is also likely to include the artists. While an exhibition catalog's purpose is to document the exhibition and artworks, experimental formats of exhibition catalogs during the later decades of the twentieth century and onwards has led to rethinking this relationships between an artwork and its documentation (Grandal Montero 2017). The resulting blurred lines between artwork and documentation have ramifications for cataloging and ethics, and are a central tenet of this article. It 
should be noted that not all works published in conjunction with an exhibition explicitly describe themselves as catalogs or even include a list of artworks. Therefore, the broader term "exhibition documentation" is utilized in this article, following the example set by ARLIS UK \& Ireland's (2000) important cataloging guidelines; so, "exhibition documentation" is used as a broad category which refers to works which in some way document exhibitions or other limited-time display of artworks, including those which are unquestionably exhibition catalogs.

The methodology employed in this article is three-fold. Literature is analysed in order to utilize existing findings born out of related scenarios, such as false memoirs (Snow 2015). Three examples of exhibition documentation are analysed, using a framework built from ideas in Snow (2015). The three examples were selected as they are known to the author for containing different examples of creative unreality. While the examples illustrate a variety of scenarios and, taken together, help to illuminate the parameters of this intriguing type of work, the three examples are not intended to be representative of artistic unreal works. Models are created from the literature analysis and from ideas elicited from the three examples of exhibition documentation.

The article has a number of purposes and limitations. Although KO is a broad set of practices, this article is chiefly concerned with bibliographic description and indexing. (The terms resource description, metadata creation and cataloging are used interchangeably throughout the article, and indexing refers to the assignment of index terms from subject indexes and thesauri.) Significantly, this article does not provide detailed catalog records of the three example art documents, nor state the preferred way to approach these items. Instead, it is chiefly concerned with the broad ethical outlook that the metadata creator is faced with before commencing description and indexing, and the consequences of decisions surrounding the ethics/aesthetics boundary. So, arguably, this article is about meta-metadata. It is also acknowledged that the scope of artistic creativity contemplated in this article is narrow in a number of ways: it is based on art rather than the arts more generally; it relates to one particular type of art documentation which is termed exhibition documentation, and 
the examples stem from exhibitions and installations; it focusses on three relatively contemporary examples of which two relate to North Korea.

This article starts by analysing the KO ethics literature which pertains specifically to applying knowledge organization systems and creating descriptions. It identifies two key works in this area by Brubaker (2018) and Snow (2015), and the latter is used as an analysis tool for artistic works. Then, three examples of documents relating to art exhibitions are dissected, each one highlighting how creative works resonate with, and challenge, discussions about metadata for other types of deceptive works. The article culminates in three models which consider creativity and deepen our understanding about unreality in applied KO. Ultimately, some interesting questions arise when art meets ethics in $\mathrm{KO}$, and this enriches our general understanding of how we should deal with documents of deception, mistruth and unreality.

\subsection{Literature analysis of applied ethics and deceptive works}

\subsection{Introducing applied ethics literature in knowledge organization}

Ethics forms an important part of research within KO. However, despite this, Fox and Reece (2012) suggest that the precise nature of what is meant by ethics is not frequently discussed, and more often relies on a "... sense of right and wrong not rigorously defined" (p. 378). As the research in this article is reliant on the existing corpus of KO ethics literature, Fox and Reece's (2012) depiction of a loose and flexible meaning of ethics will be adopted: so, in this article, the term ethics will be used very generally to mean discussions which evoke morality in its broadest sense, without discussions about how this fits into the branch of philosophy or its associated principles.

A range of topics and perspectives make up ethics KO discourse. Some of the discourse could be categorized as being focussed on particular groups of people, such as gender (for example, Olson 2007, Fox 2014, Adler 2016). However, there is also often a separation in the literature between the following: discussions about ethical issues in knowledge organization systems (KOSs); and, works 
which consider the processes of constructing metadata for documents, including the application of those KOSs to individual documents. While both concern applied ethics, the second category is of most relevance to this article. The applied ethics of constructing metadata includes a variety of different approaches. For example, some works focus on codes and guidelines for doing ethical KO in practice (for instance, Shoemaker 2015, Bair 2005); others focus on specific scenarios or types of material, such as ethical issues in authority control for zine authors (Fox and Swickard 2019) or dealing with so-called "bad books" (Homan 2012). Therefore, this article utilizes the KO applied ethics literature which discusses ethical codes and guidelines, yet uses it to discuss a very specific scenario involving art documentation. Literature which discusses so-called deceptive works, provide the foundations for analysing the novel addition of aesthetics to the ethical conundrums. Therefore, the KO literature analysis focuses on works within two areas: the development of ethical codes of practice in the Anglo-American cataloging communities and KO for deceptive works.

\subsection{Ethical codes of practice and ethical guidelines}

Bair's (2005) seminal article discusses the principles pertaining to ethical responsibilities for catalogers and she introduces a code of ethics specifically for catalogers. However, this code was not adopted by the community; Shoemaker (2015) suggests that one reason for this is that it is the creation of an individual rather than a collection of librarians. Fox and Reece (2012) also present a set of ethical guidelines which examines what is meant by morality in KO. Their guidelines include the duty to care about what happens, the idea of being rigid but with some mitigation, and the importance of considering the consequences of KO decisions (Fox and Reece 2012). The final point here may be especially pertinent to cataloging works about art, where the documents accompanying artworks can be part of the aesthetic experience of the artwork and there may be corresponding consequences of including or not including information in the metadata. Ultimately, Fox and Reece's (2012) guidelines relate more to classification than description, so will not be used further in this article. 
Snow (2015) offers an alternative to an ethical code of practice. In Snow's (2015) analysis and discussion about the ethical dilemmas presented by false memoirs, which is discussed in detail below, she utilizes a set of ethical principles which are extracted from the IFLA Statement of International Cataloging Principles (ICP). These statements, produced by the cataloging section of IFLA (Galeffi et al. 2017), are originally based on the 1961 Paris principles of cataloging. The ICP was first published in 2009, which is the version used in Snow (2015). The most recent version will be used in this article, and dates from 2017. (There are some differences between the 2009 and 2017 versions, in the number of principles and the short descriptions of the principles. However, the differences are not substantive for the topic of discussion in this article.) Snow (2015) draws upon three of these principles in her discussion: 2.1 Convenience of User, 2.3 Representation, and 2.4 Accuracy. In the ICP (Galeffi et al. 2017), the first principle is given as the most important and if necessary, the one that should be prioritized (Galeffi et al. 2017): "2.1 Convenience of the user. Convenience means that all efforts should be made to keep all data comprehensible and suitable for the users." This means that from an ethical perspective, the users' needs should be prioritized when faced with difficult cataloging decisions. The other two principles discussed by Snow (2015) are as follows: "2.3 Representation. A description should represent a resource as it appears ..." (Galeffi et al. 2017) and "2.4 Accuracy. Bibliographic and authority data should be an accurate portrayal of the entity described." (Galeffi et al. 2017). Note that the full description for ICP 2.3 discusses authority control and controlled names, although it can be appropriated to cover all aspects of cataloging including the descriptive elements as well.

It is important to consider who the ethical obligations of the catalogers are to. Bair (2005) gives a list of six interconnected and overlapping groups: society, institutions that catalogers work at, library users, librarians, the profession, and generally to humans. It is interesting to note that the creators of the resources do not feature explicitly in this list, nor in many other discussions about ethical obligations, and this omission will be explored in the discussions about metadata for artistic materials. 
Finally, in the last few years, cataloging communities in the U.S., Canada and the U.K. have been collaborating on developing a code of ethics for catalogers, under the guise of the Cataloging Ethics Steering Committee (2020a). In June 2020 the first draft was released, and the second draft is the most current version available at the time of writing (Cataloging Ethics Steering Committee 2020a). As this work is quite broad in nature, there is little which is germane to the detailed ethical decisions about individual metadata elements that form the basis of this article. Two small points are worth mentioning, however. The first of the nine principles says that "we catalogue resources in our collections with the end-user in mind" (Cataloging Ethics Steering Committee 2020b); this could be viewed as correlating with ICP 2.1 (Galeffi et al. 2017) which concerns the convenience of the user, though there is no suggestion in the draft code of ethics, unlike in the ICP, that this principle should trump the other principles. Creators are mentioned in the new code of ethics (Cataloging Ethics Steering Committee 2020b) , unlike in the other principles and research discussed so far. However, as this occurs as part of the principle concerning bias (Cataloging Ethics Steering Committee 2020b), this comment seems to refer to creators as general human beings rather than to their creative vision, and is therefore not directly relevant to the discussion. So, while there is now a draft of a new code of cataloging ethics, the ICP principles identified and utilized by Snow (2015) are more useful for the analysis in this article. Therefore, ICP 2.1, ICP 2.3 and ICP 2.4 will be used as the framework for discussing art-related ethical questions.

\subsection{Deception and deceptive works}

A significant and relevant topic in applied ethics in $\mathrm{KO}$ concerns the organization and description of works which are "of questionable authorship and authenticity or veracity" (Brubaker 2018, p. 9). Two sources are particularly useful here: Brubaker's book of examples of deceptive works (2018) and Snow's (2015) article analysing the ethical issues with false memoirs. They are important to the discussion in this article for two main reasons. First, they discuss works which are akin to the artrelated examples, but as will be shown have important differences. Second, the framework 
developed by Snow (2015) to discuss one specific example of deceptive work, can be utilized to interrogate another.

Brubaker's 2018 book is centered on a set of example problematic works, including memoirs, autobiographies, fictional novels, and poetry. Each work is outlined and the author gives her opinion on what solution should (or should not) be adopted. Two aspects of this book are of interest to this article. First, there is discussion about categorizing the deceptions. Brubaker (2018) divides the deceptions into two broad categories: the author misrepresented themselves in some way; nonfiction works which are either actually fictional or include significant mistruths. This is useful as it serves as a broad categorization of deceptive works, where the dividing factor is whether the deception centers on the author or the work. It is probably the latter which is most similar to the art documentation considered in this article. Second, Brubaker (2018) very briefly mentions the issue of ethics and creativity, which is the topic of this article. She (Brubaker 2018, p. 127) describes examples where “... deceptions regarding authorship or origin are central to the author's creative vision, and the reading experience is enhanced by the reader's growing awareness of the deception", and suggests there is sometimes a tension between accuracy and art. However, there are a few significant differences between these statements and the focus of this article. The art documentation considered in this article do not generally focus on authorship or origin. Also, in the examples explored in this article, awareness of the deception by the audience is not necessarily a desired outcome.

Snow's (2015) article focusses on a specific type of deceptive work: the false memoir. This is a work which describes a period of time in an author's life, but the truthfulness of the resource is questioned in a public way (Snow 2015). Snow (2015) discusses the ethical problems presented by such works, using specific points from the ICP pertaining to ethics (as discussed above). Snow (2015) concludes that for false memoirs, accuracy of what the resource contains (ICP 2.4) might be in opposition to being faithful to how that resource self-represents (ICP 2.3). In other words, accuracy 
and self-representation cannot always coexist. Snow's (2015) suggestion is that the answer may lie in representing multiple realities in order to be useful to readers, such as fiction and nonfiction subject headings in the same catalog record (Snow 2015). This insightful discussion can be transformed into a useful framework for the analysis of art documentation: self-representation (ICP 2.3) + accuracy (ICP 2.4) = best convenience to the user (ICP 2.1). This is visualized in Figure 1. So, the analysis of the three examples of art documentation will do the following: it will see how accuracy and self-representation interact; it will consider the impact of including multiple realities, including whether this would create convenience to the user; and, perhaps most significantly, the art documentation examples will be mined to see what additional issues and perspectives art documentation adds to metadata creation for deceptive works.

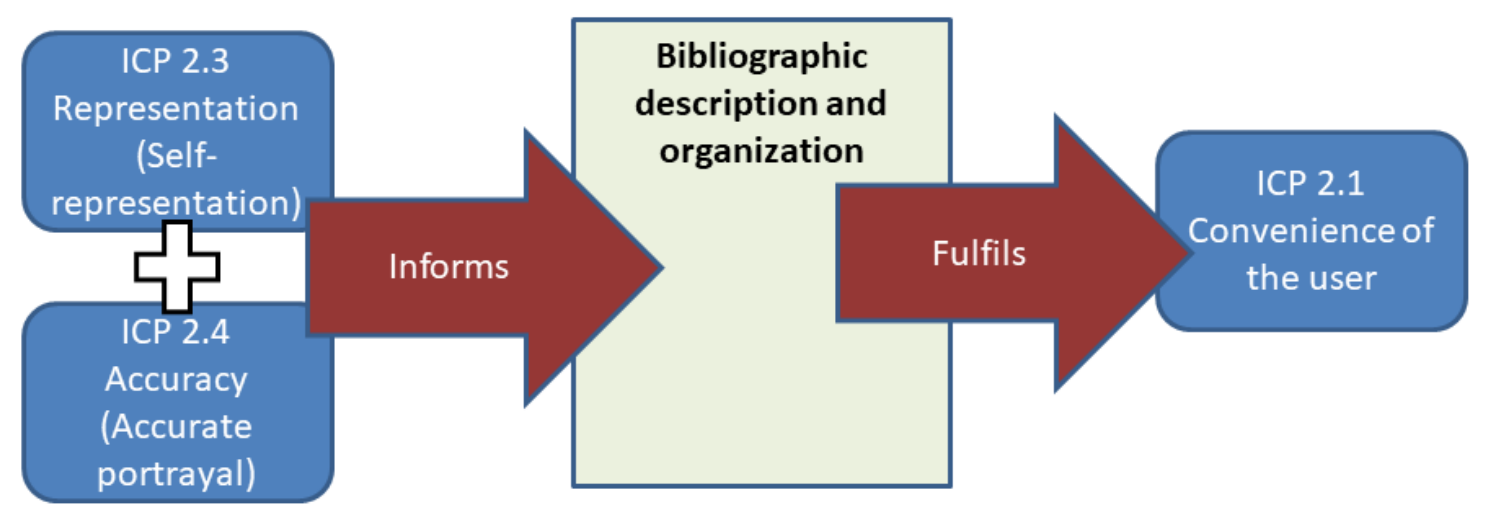

Figure 1: Using Snow (2015) as a framework to analyse deceptive works

Two other aspects of Snow (2015) are significant for this article. The first concerns notes, which are a typical way to explain controversies on catalog records (Homan 2012, Brubaker 2018). Snow (2015) explains that making these notes requires high skill from catalogers and time, especially in making these notes as non-judgemental as possible. Second, false memoirs open up a question about the temporal dimension: is there an obligation to return to metadata once a deception has been discovered (Snow 2015)? This temporal aspect also needs consideration for art documentation. 
The literature analysis has identified the importance of studying applied ethics in $\mathrm{KO}$, in particular when trying to describe and organize works which have an element of deception. However, much of the existing research has focussed on examples which are different from artistic scenarios in the reasons for the deceptions. Though deception-for-creativity is identified by Brubaker (2018), there is no detailed discussion of this phenomenon. Therefore, the literature analysis has identified an important gap which this article will start filling: an in-depth exploration and conceptualization of the ethics of KO when the deception is for artistic purposes.

\subsection{The ethics of knowledge organization for unreal works about art}

\subsection{Introducing unreal art documentation}

Art documentation contains some intriguing treatments of unreality, and these illuminate issues concerning the ethics of their knowledge organization. On the surface, this art documentation shares similarities with the deceptive works analysed and categorized by authors such as Snow (2015) and Brubaker (2018). They are works about art (which could in some circumstances be considered artworks in their own right) where what is presented in the published resource is not necessarily a depiction of reality or the truth. Note that unlike genres of works in other artforms such as say novels or plays, art documentation is not traditionally assumed to be unreal in the same way. This is also reflected in their subject cataloging: the Library of Congress Subject Heading form subdivision of "Exhibitions" used for exhibition catalogs, potentially signifies to a library user a different relationship to truth than the form subdivision of "Fiction". However, although the unreality might be expected, there is a significant difference in intention between art documentation with unreal aspects and, say, false memoirs. In the works under consideration in this article, there is every reason to believe that any intention for misleading the reader is for artistic purposes. (The ability to ascertain the intentions of the creators of such works is not straightforward, as will be seen in the examples.) 
Terminology for these types of works presents a challenge. Brubaker (2018) uses the term "deceptive works" to discuss the broad category of works where there is a mismatch between what is presented and what is real, and which covers specific types such as false memoirs. However, the Oxford English Dictionary defines the act of deceiving as "To cause to believe what is false; to mislead as to a matter of fact, lead into error, impose upon, delude, 'take in"' ("Deceive, v., $2 a$ " 1989). While some of these explanations could apply to artistic scenarios, other parts of this definition imply that the action is intended for gain or to cause harm. This makes using the term "deceptive works" problematic for these works, and similar terms such as "misleading works" also have a flavour of negativity. Another possibility is to use the term "fiction" or "fictional", as one definition of fiction in the Oxford English Dictionary is quite appropriate for this scenario: "The action of 'feigning' or inventing imaginary incidents, existences, states of things, etc., whether for the purpose of deception or otherwise" ("fiction, $n ., 4 a " 1989$ ). However, this is problematic due to the term's additional usage as a specific type of literature ("Fiction, $n ., 4 a$ " 1989). So, an alternative term, "unreal works", is used instead. The adjective "Unreal" is defined in the Oxford English Dictionary as "Imaginary, illusory, intangible; not real” (“Unreal, adj. (and int.) and n., 1." 2014), and arguably best encapsulates this aspect of the artistic works while reducing the possibility of misrepresentation. However, it is acknowledged that no term will be a perfect fit and that some of the rejected terms are useful as near-synonyms.

There is a section of discourse in aesthetics and art theory devoted to the idea of "artistic truth" (see for example, Heyl 1950, Price 1949), which asks what it means for an artwork to be true and whether truth is an important quality. This could be seen as a precedent for contemporary discussions about truthiness in art (for example, Armstrong et al. 2012), which consider the blurred edges between reality and unreality, and between truth and mistruth. So, while this article focuses on KO issues, it is worth remembering that these discussions about the implications for KO when dealing with the unreal aspects of art documentation, could also be linked to the aesthetics perspective of artistic truth and truthiness. 
To examine the ethical considerations presented by cataloging and indexing artistic unreal works, three examples are analysed. The analysis uses the framework discussed above (see Figure 1), which utilizes Snow's (2015) findings about false memoirs. Information about the works and their cataloging is taken from the following sources: the works themselves, secondary information about the works, and from the catalog records on the XXXX library [removed to protect author anonymity] catalog. Note that the catalog records were edited or created by the author of this article, so are not a completely independent source.

\subsection{Example 1: Die Deutsches Informationsbibliothek Pjöngjang by Sara}

\section{van der Heide}

The first example is exhibition documentation relating to the artist Sara van der Heide and corresponds to her exhibition shown as part of the $5^{\text {th }}$ Guangzhou Triennial, from December 11 , 2015 to April 10, 2016 (Heider et al. 2016). The documentation consists of five booklets. Four of these are the exhibition catalog, with each of the four booklets containing the catalog in a different language (English, German, Chinese, and Korean). The fifth booklet consists of essays, reflections and images and is entitled "Critical reflections and documentation of The German Library Pyongyang".

The documents represent a set of artistic events by Sara van der Heide. The installation is described by the chief curator of the Biennial as a historical reconstruction of the Deutsches Informationsbibliothek Pjöngjang but also as a space for contemplating political and cultural issues (Slager 2016). The real-life but now disbanded Deutsches Informationsbibliothek Pjöngjang, was at the Goethe-Institut's Information Centre Pyongyang and the center was open from June 2004 for five years (Heide et al. 2016). Sara van der Heide describes her work as an "intervention ... an imaginary transformation of the current geography of the existing library" (Heide et al. 2016, English exhibition catalog, 1). In this installation, a real-life space in one country is reconstructed in another, making the role of Deutsches Informationsbibliothek Pjöngjang both real (it did exist) and 
unreal (it is reconstructed for this installation). How those creating metadata should deal with the concept of the Deutsches Informationsbibliothek Pjöngjang is the key ethical issue under discussion.

The reconstruction element of the Deutsches Informationsbibliothek Pjöngjang is described within the documents being catalogd. Nevertheless, the fact that this is not actually the original Deutsches Informationsbibliothek Pjöngjang nor takes place in Pyongyang is not obvious from the title of the documents. Arguably this requires some careful reading to unpick, and there is a possibility that the title of the work could be misleading to users. Furthermore, though the exhibition's location on the title pages makes it obvious that this did not take place in Pyongyang, it is not obvious that Deutsches Informationsbibliothek Pjöngjang really did exist. Therefore, if Snow's (2015) multiple realities were employed here, then a combination of the title and subject of Deutsches Informationsbibliothek Pjöngjang (self-representation, ICP 2.3) with a note explaining the reconstruction element (accurate portrayal, ICP 2.4) would be a helpful solution and of maximum convenience to the user. So, in this example the artistic unreal can be adequately dealt with using Snow's (2015) conclusions for false memoirs.

\subsection{Example 2: The Pyongyang Times by the Random Institute}

The second example is entitled The Pyongyang Times. This is documentation from an exhibition which took place April 9-12, 2016, on the 23rd floor of the Yanggakdo International Hotel in Pjöngjang, North Korea (Random Institute 2016). The exhibition was entitled "All the lights we cannot see", and featured the work of nine international artists (Random Institute 2016). The exhibition was arranged by the Random Institute in Zürich, who also published the catalog, and the exhibition was curated by Anna Hugo and Sandino Scheidegger (Random Institute 2016). There are two broad sets of aesthetic-ethical KO questions raised by this example: the manipulated aspect of the documentation and the issue of secrecy around the exhibition.

The printed documentation takes the form of a newspaper entitled The Pyongyang Times. There is an article about the art exhibition on page 3, while the rest of the issue deals with other news, 
politics, culture, and so on. However, the catalog is actually a manipulated version of this issue of The Pyongyang Times, an English-language newspaper produced in North Korea. In the most part, the catalog replicates the actual issue of the newspaper, including its masthead, numbering (No. 15, 2894) and date (April 15, 2016), and the majority of the articles. The main difference between the real Pyongyang Times (2016) and the unreal catalog (Random Institute 2016) is the insertion of the article about the exhibition, which apes the stylistic conventions of the host publication and replaces a story about pump factories by Sun (2016). Less explicit signs appear at the end of the publication that this is not the newspaper Pyongyang Times: there is an attribution to the Random Institute and a handwritten copy number. Ultimately, this example is different in essence from examples such as false memoirs, as the website for the catalog (Random Institute 2020) is transparent about this manipulation and there are small indications on the catalog itself.

The manipulated nature of this documentation gives rise to a question about the most suitable title and also whether its manipulation should be explained within the catalog description. The exhibition documentation has a title of The Pyongyang Times on the documentation; yet, there is a question about whether this is an accurate portrayal of the title, considering it is a manipulation of this newspaper. Applying Snow's (2015) conclusion about multiple realities helping the convenience of readers, at first seems useful for this scenario: this would see the title in the metadata as The Pyongyang Times, with the addition of a note describing the manipulation and a link (with appropriate designator) to The Pyongyang Times (newspaper). However, creators' intentions come into play: it is assumed that the creators want to give the illusion that there was an article about this exhibition in The Pyongyang Times (newspaper). So, notes and links which foretell the manipulation within this document also eliminate the reader's opportunity to experience this unreal world, if the reader approaches the document through the library catalog. This sets up an interesting relationship between creator, cataloger and user. 
Secrecy also presents ethical considerations for those making this resource discoverable. The Random Institute (2020) state that “... the entire project, from the art on display to the story behind it, was committed to silence". Random Institute (2020) also say that the only surviving documents are some installation views and a short mention on the CVs of artists who participated, who were then not allowed to say anything about the exhibition when they would inevitably be asked to elaborate. However, there is definitely an online presence for the exhibition which appears to have been perpetrated by the authors: for instance, the Artcritical review by Starnes (2016) is evidence that the digital footprint of the exhibition was shared. Therefore, by creating and sharing bibliographic metadata for The Pyongyang Times, KO practitioners are automatically entering an ethical plane.

To start, just creating a catalog record for this document needs consideration, as it could be argued that the logical conclusion to the curators and authors' wishes for secrecy would be no catalog record at all. This follows on from earlier discussion about creators' wishes playing an important part of ethics in KO. A similar ethical question arises about notes and indexing for the curators and artists, which would digitally link this exhibition to other works in the library catalog by the same artists and curators. (These echo similar issues found in authority control where individuals or organizations do not want to be identified as creators of works or with particular appellations, albeit usually for very different reasons (for example, see Fox and Swickard 2018)). However, extra complexities arise: the list of artists and title of the exhibition are not included in The Pyongyang Times, but are freely mentioned by the Random Institute on their website (Random Institute 2020) and reviews (for example, Starnes 2016). The secondary source by the authors (Random Institute) juxtaposes the details of the exhibition with their wishes about secrecy. This asks questions about how imperative it should be to follow creators' wishes and how a creator's wish may not be a single, simple, explicit instruction. Furthermore, the secrecy issue also illuminates the fissure in art cataloging between metadata about the exhibition and metadata about the exhibition documentation. Ultimately, The Pyongyang Times example highlight the ethical complexities of 
knowledge organization when the flow of information, such as manipulated documents and withholding information, is part of the performative nature of these documents.

\subsection{Example 3. Wall and Tower by Yael Bartana}

The third example is by the artist Yael Bartana. Her 2009 film, Wall and Tower ("Mur i wieża") is the second part of her "And Europe will be stunned" trilogy (Bartana 2020), and was exhibited as part of (and the winner of) the $4^{\text {th }}$ Arts Mundi prize in 2010 (Arts Mundi 2020). The film has an element of the unreal, with an Artnews article (Cembalest 2013) describing it as a "mockumentary". Two posters (artist multiples) accompanied the film and these are the documents under discussion: "Wall and Tower D.I.Y." (Bartana 2009b) and "The Jewish Renaissance Movement in Poland: a Manifesto" (Bartana 2009a). The first includes diagrams which are in the style of D.I.Y. pictorial instructions, and the second includes the logo and manifesto for the Jewish Renaissance Movement in Poland.

The KO ethics question in these documents relates to the Jewish Renaissance Movement in Poland: there is a question about the realness of this movement, which then generates a question about how to represent this potential un-realness in the metadata associated with the posters. According to the manifesto (Bartana 2009a), the Jewish Renaissance Movement in Poland was an organization whose purpose was to organize a return to Poland of the Jewish population. However, it seems that in 2009 this movement existed only within the universe of Bartana's artworks. According to the definition of a movement in the Oxford English Dictionary ("Movement, n., 8a" 2003), a key ingredient in a movement is that it must involve multiple people working towards the same thing; the Bartana example does not appear to have this multiple aspect.

The question of ethics arises when contemplating a note about the unreal nature of the organization as part of the metadata, and then whether to potentially add more legitimacy to the organization by indexing it. Following ICP 2.3 (self-representation) would mean not including a note questioning the movement's realness, and that the movement should be indexed. Conversely, following ICP 2.4 (accurate portrayal) would mean including both a note about the possible unreal element of the 
movement, plus a further decision to be made about whether it should be indexed as a fictitious body or not at all. If multiple realities were adopted here (Snow 2015), there would be some extra complexities. First, this example is not just a question of whether the real or unreal version should be represented in the metadata; instead, reality is blurred. The Jewish Renaissance Movement in Poland is real-ish, but our cataloging systems cannot (usually) account for this ambiguity. Second, the artist's wishes are significant: following a combined approach also means changing the intended experience of the user, and probably going against the wishes of the creator. Furthermore, unlike the previous examples, Jewish Renaissance Movement in Poland's unreal(ish) status is not explicitly commented upon in the exhibition documentation and is not easy to ascertain through authoritative sources. In fact, its realness is quite a struggle to establish, to the extent that it is reliant on conjecture. This suggests that transparency about a deception can vary, even within artistic examples. It could be hypothesized that by not acknowledging the unreal element, the creator is more committed to this unreal experience and perhaps their wishes take on more, not less, importance when balancing up the cataloger's competing considerations.

However, there is a twist to this particular example. Bartana continued working on these themes: the movement which was unreal-ish in 2009 , later becomes real. Cembalest (2013) said the artist “... brought her campaign into another reality when she turned the Jewish Renaissance Movement into a real entity". Hence, there is now a question about whether the metadata should be altered postfacto for this work, to represent what has since happened to the movement. This is particularly interesting when compared to the example of false memoirs. For example, Snow (2015) discusses the ethical responsibilities around updating the metadata when catalogers find that a work that describes itself as factual is later found to be partially or entirely fictional. However, the Bartana example presents a different situation. In the Bartana example, the reality changed with time; for false memoirs, it is the information known about the reality which has been updated. So, the Bartana examples emphasize the consequences of cataloging happening in a temporal frame, and 
the importance to KO of understanding the relationship between time, reality and information about that reality.

\subsection{Impact on specific metadata elements}

The discussion about these three examples of art documentation has described the broad areas and questions raised. It is now worth briefly considering the specific elements which might be impacted by these questions. The specific types of information which emerged from the analysis of the three examples is listed in the first column of Table 1, and for each specific type of information, the example(s) it appeared in is also indicated. To give some useful context, the equivalent or nearequivalent RDA attribute(s) or relationship is given in the second column alongside its current guideline numbering ("RDA Toolkit" 2020). Additionally, the corresponding MARC21 field is also given in the third column (Library of Congress 2020b), and where the RDA element is only mapped to specific MARC21 subfields, the specific subfields are also specified using the convention of a dollar sign (Library of Congress 2020b). While most values in the MARC21 column refers to bibliographic metadata, one element is also concerned with authority metadata (Library of Congress 2020a).

\begin{tabular}{|c|c|c|c|c|c|}
\hline Element impacted & $\begin{array}{l}\text { Equivalent RDA attribute(s) } \\
\text { and/or relationship }\end{array}$ & $\begin{array}{l}\text { Equivalent } \\
\text { MARC21 } \\
\text { field }\end{array}$ & $\begin{array}{l}\text { Found } \\
\text { in } \\
\text { Ex. } 1\end{array}$ & $\begin{array}{l}\text { Found } \\
\text { in } \\
\text { Ex. } 2\end{array}$ & $\begin{array}{l}\text { Found } \\
\text { in } \\
\text { Ex. } 3\end{array}$ \\
\hline Title of documentation & $\begin{array}{l}\text { Title proper (2.3.2.) and } \\
\text { Other title information } \\
(2.3 .4)\end{array}$ & $\begin{array}{l}245 \$ a \\
245 \$ b\end{array}$ & $\mathrm{x}$ & $\mathrm{x}$ & \\
\hline Variant title & Variant title (2.3.6) & 246 & & $\mathrm{x}$ & \\
\hline Publication information & $\begin{array}{l}\text { Place of publication (2.8.2) } \\
\text { and Publisher's name (2.8.4) }\end{array}$ & $\begin{array}{l}264 \$ a \\
264 \$ b\end{array}$ & & $\mathrm{x}$ & \\
\hline Note explaining unreal-ness & $\begin{array}{l}\text { Note on manifestation } \\
(2.17)\end{array}$ & 500 & $\mathrm{x}$ & $\mathrm{x}$ & $\mathrm{x}$ \\
\hline Note listing featured artists & $\begin{array}{l}\text { Note on manifestation } \\
(2.17)\end{array}$ & 500 & & $x$ & \\
\hline $\begin{array}{l}\text { Unreal/Unreal-ish } \\
\text { organization as subject }\end{array}$ & [Not in RDA] & 610 & $x$ & & $x$ \\
\hline Artists and curators & $\begin{array}{l}\text { Contributor (20.2) and } \\
\text { Relationship designators for } \\
\text { contributor (I.3.1) }\end{array}$ & 700 & & $x$ & \\
\hline $\begin{array}{l}\text { Unreal/Unreal-ish } \\
\text { organization as agent }\end{array}$ & $\begin{array}{l}\text { Contributor (20.2), } \\
\text { Relationship designators for } \\
\text { contributor (I.3.1) and } \\
\text { Identifying corporate bodies }\end{array}$ & $\begin{array}{l}710 \\
\text { and the } \\
\text { related } \\
\text { authority }\end{array}$ & & & $\mathrm{x}$ \\
\hline
\end{tabular}




\begin{tabular}{|l|l|l|l|l|l|}
\hline & $(11)$ & record & & & \\
\hline $\begin{array}{l}\text { Relationship between real } \\
\text { and unreal work }\end{array}$ & $\begin{array}{l}\text { Related work (25.1.1) and } \\
\text { Relationship designators for } \\
\text { related works (J.2) }\end{array}$ & $\begin{array}{l}700,710, \\
711 \text { or 730 }\end{array}$ & X & \\
\hline
\end{tabular}

Table 1: Elements impacted in three artistic examples

We can see a number of important ideas from Table 1. It appears that the information from these three examples is centred upon quite a few different areas, including title, publication, notes, contributors and related works. However, if more works were added to future analysis, undoubtedly more elements would emerge, so this table is not at all exhaustive. The extremely small number of examples means we can make no assumptions about the frequency of the different elements; however, from this information it is sensible to suggest that elements related to title, notes and related agents or works appear to be reasonably likely to be affected by unreal-ness in exhibition documentation. It is also interesting to note that all of these examples of elements would usually be user-facing, rather than for internal use.

A further question emerges regarding classification and subject indexing. Exhibition documentation is treated differently in various global, general classification schemes, and art libraries are also known for their high incidence of adapting classification schemes (Ferrari 2000; Lee 2011). Ultimately, the impact of unreal elements on the classification of exhibition documentation would depend on the organization's classification scheme and any local adaptations, although the above three examples are unlikely to be impacted by classification schemes which chiefly categorize by solo artist, artistic medium, or exhibition venue. However, format categoriztion might have an impact for The Pyongyang Times example, where the ethical considerations around manipulation, findability, and secrecy - alongside other practical considerations to do with preservation and size - might influence the decision about whether to categorize this art documentation alongside other print newspapers. The three examples also show how considering unreal aspects might have an impact on subject indexing, including whether to include an unreal organization as a subject or not, and if so, whether to indicate the fictitious nature of the organization within the index term. So, while this discussion does not specify exactly which elements and aspects of knowledge organization will be 
affected by unreal aspects, it does illuminate some of the possible ways that unreal aspects of art documentation works might manifest themselves in an applied setting.

\subsection{Modelling knowledge organization for artistic unreality}

Examining these three examples of art documentation has teased out some important findings. Two key ideas emerge: the importance of creativity and the role of the creators in making ethical KO decisions; that unreality and reality are important to KO and are complex concepts. These are now built into three models which focus on artistic reality, while also expanding our general understanding of dealing with deception and unreality in KO.

\subsection{Model 1: Creators' wishes within the ethics of knowledge organization}

The analysis of the three examples highlighted a significant consideration: the position of the creator when dealing with unreal-ness in art documentation. However, before examining this in detail, it is useful to contemplate why the artists' wishes should be accommodated. In other artforms, honoring the wishes of the creator is so inbuilt into the artistic process that it has historically been an assumption; for instance, in musical performance, the need to obey the composer's intentions was an almost unquestioned assumption (Dipert 1980) until recent decades. While artworks mostly do not have the same dependence on intermediaries as the performing arts, some of these artistic examples do share an essence of this performative aspect and thus this assumption could be borrowed. Furthermore, there is also a residual moral imperative to respect the wishes of creators, which is in some aspects is also enshrined in intellectual property law.

The examples illuminated the role of the creator in the ethics of $\mathrm{KO}$, and furthermore, how fulfilling the creator's wishes could be in opposition to other ethical principles such as accuracy. For example, in The Pyongyang Times example, the needs of the creator would favour honoring the artistic experience for users, which means describing the document as though it were a real issue of the 
newspaper. Yet, doing this would arguably not be an accurate portrayal of the document, and could lead to inconvenience for those seeking the document via its exhibition name or those actually wanting the Pyongyang Times (newspaper). (Here, the term "inconvenience" is used to express the situation when a reader looks for something on a catalog, and the search results are either longer than they would be or do not include the desired document, due to the decisions made by the cataloger around title.) The idea of an obligation to creators is not present, or at least not explicit, in various discussions about ethical obligations in cataloging. As discussed in the literature review, Bair (2005) discusses groups to whom catalogers have obligations: society, employer, clients, colleagues and other professional organizations, the profession as a whole, and individuals. The creators of the bibliographic work are not mentioned. Therefore, artistic unreal works uncover a potential additional ethical area and obligation.

The area of creators' wishes and visions opens up a rich seam of relationships, complexities and understanding. First, there is clearly an important relationship between the creators' wishes and the convenience of the readers. Honoring the creators' wishes may mean possible inconvenience to the readers, especially if information is omitted. This sets up a vector of importance, and starts asking how metadata creators prioritize the competing needs of the various groups listed in Bair (2005) and others. (Note that in the examples seen, the purpose of following the creators' artistic vision is also to benefit the readers, as it is their experience of the documentation which is at stake.) Second, it is not necessarily straightforward to determine the obligations to the creator, as they are likely to be implicit. For example, the creators' desires for The Pyongyang Times are implied from looking at the spaces between the document (looks like a newspaper) and what it actually is (a manipulated document), combined with secondary sources and general broad ideas about art. The proposal that the creators want the readers to think (at least in the first instance) that this is a real copy of the newspaper The Pyongyang Times is an assumption, so all the subsequent cataloguing implications are based on this assumption. Third, The Pyongyang Times example highlights that there is a difference between the document and the creator in terms of ethical considerations. In other 
words, just following the document alone will not necessarily also take into account the document creators' wishes.

So, a fourth ethical obligation could be added to the three identified by Snow (2015): wishes of the creator. (Note that this is given in the singular, to match the language used in the ICP obligations which talks about user rather than users.) Snow's (2015) framework and research for deceptive works suggested that the best way to achieve the most convenience to the user is a combination of self-description and accurate portrayal, which could be written as "self-representation (ICP 2.3) + accuracy (ICP 2.4) = best convenience to the user (ICP 2.1)". Adding the creators' wishes extends this as follows: "self-representation (ICP 2.3) + accuracy (ICP 2.4) = best convenience to the user (ICP 2.1) + creators' wishes (new)". In other words, the required result is to inconvenience the reader as little as possible while also following the projected wishes of the creators; this is achieved through some combination of self-description and accurate portrayal. This is visualized in Figure 2, which provides a model of the competing ethical demands, and shows how these interact with the bibliographic description and organization. This extends a similar visualization seen in Figure 1 to include the extra balancing needed to incorporate the obligation to creators. The model also shows how the principles on the left-hand side pertain to the document, while those on the right pertain to different sets of agents (using the language of IFLA-LRM here). It could be argued that the authors of false memoirs actually have similar wishes to the creators of the three analysed artistic examples. The difference between the situations is one of motive and this difference suggests that there are other factors at play in terms of unreality. These will now be explored further. 


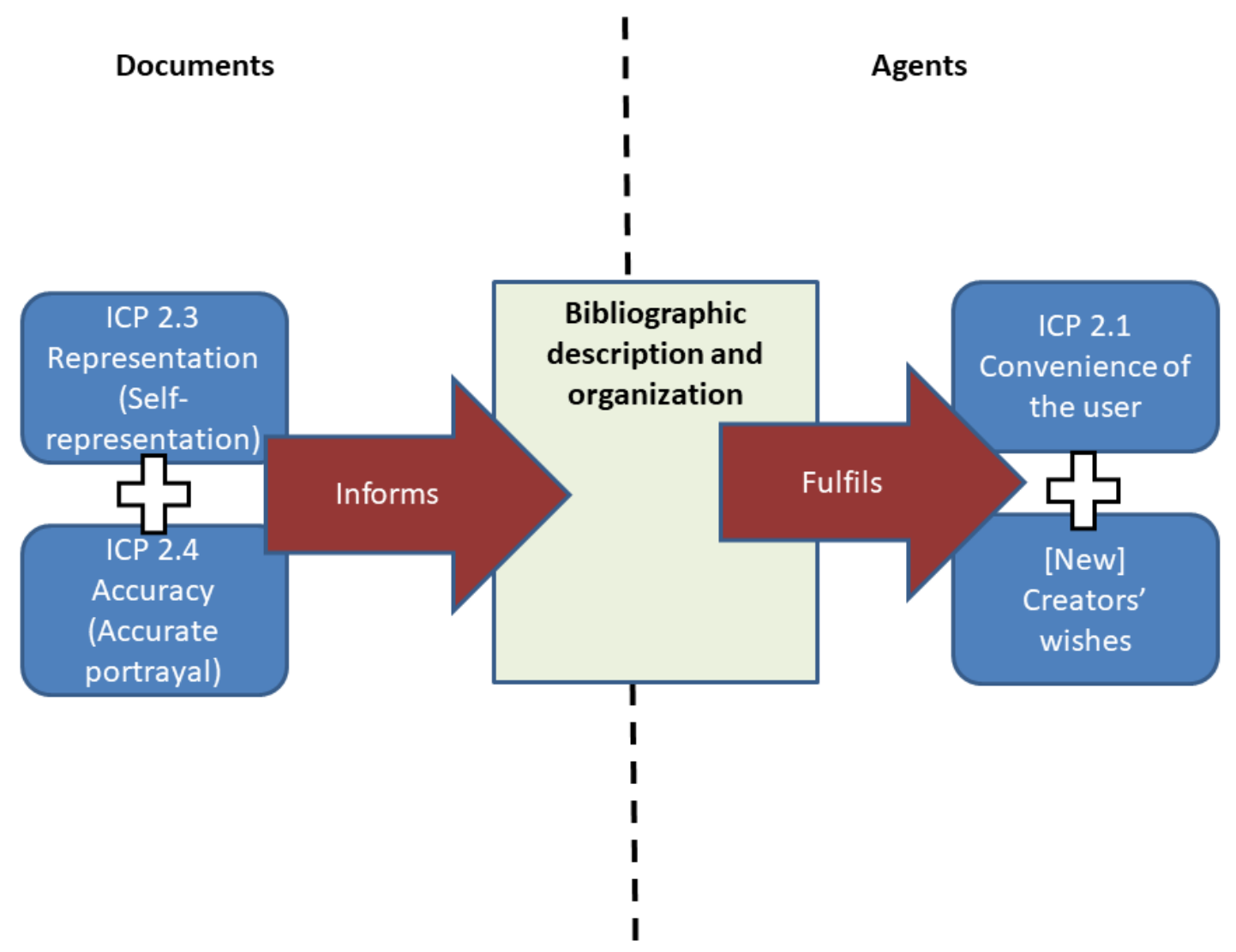

Figure 2: Model 1: Creators' wishes within the ethics of KO

\subsection{Model 2: Concentric circles of unreality}

The exploration of the three examples highlights that the unreal element is not uniform in art documentation. For example, The Pyongyang Times had unreal aspects in the format of the exhibition documentation, which borrowed an existing publication; the Heide example had its unreal element within the art itself, where the artwork being discussed in the exhibition documents was an amalgamation of the real and unreal; the Bartana example's unreal-ness is in the subject of the exhibition. It is possible that ethical decisions about the KO of such documents might differ depending on where the unreality sits: potential misleading in the title of a document (for instance, The Pyongyang Times) might lead to a bigger imperative to explain the unreal-ness to the user than an unreal element in the artworks (for instance, Heide) or the subject of the artwork (for example, Bartana). This is partly to do with expectation: artworks are expected to have creative 
interpretations of reality - though, not to the extent of say a novel - but this is less expected in the art's documentation. Furthermore, the difference between the three examples is the distance between the unreal aspect in relation to the act of metadata creation and indexing. This could be considered a "metadata librarian's gaze". This links to the question of what exactly is being cataloged in exhibition documentation, which sees contemporary bibliographic cataloging practices focus on art documentation rather than the artwork or exhibition. Three types of unreality are visualized in Figure 3. This delineates unreal elements of art documentation in comparison to unreal elements within the artworks, showing how unreal elements in the artwork are more removed from the bibliographic catalog records than those which exist as part of the documentation of those artworks. Unreal subjects of artworks are also represented in Figure 3, as part of the artwork but a further step away. Understanding the different placings of the unreality helps us to understand why different unreal elements may be treated differently by those creating metadata.

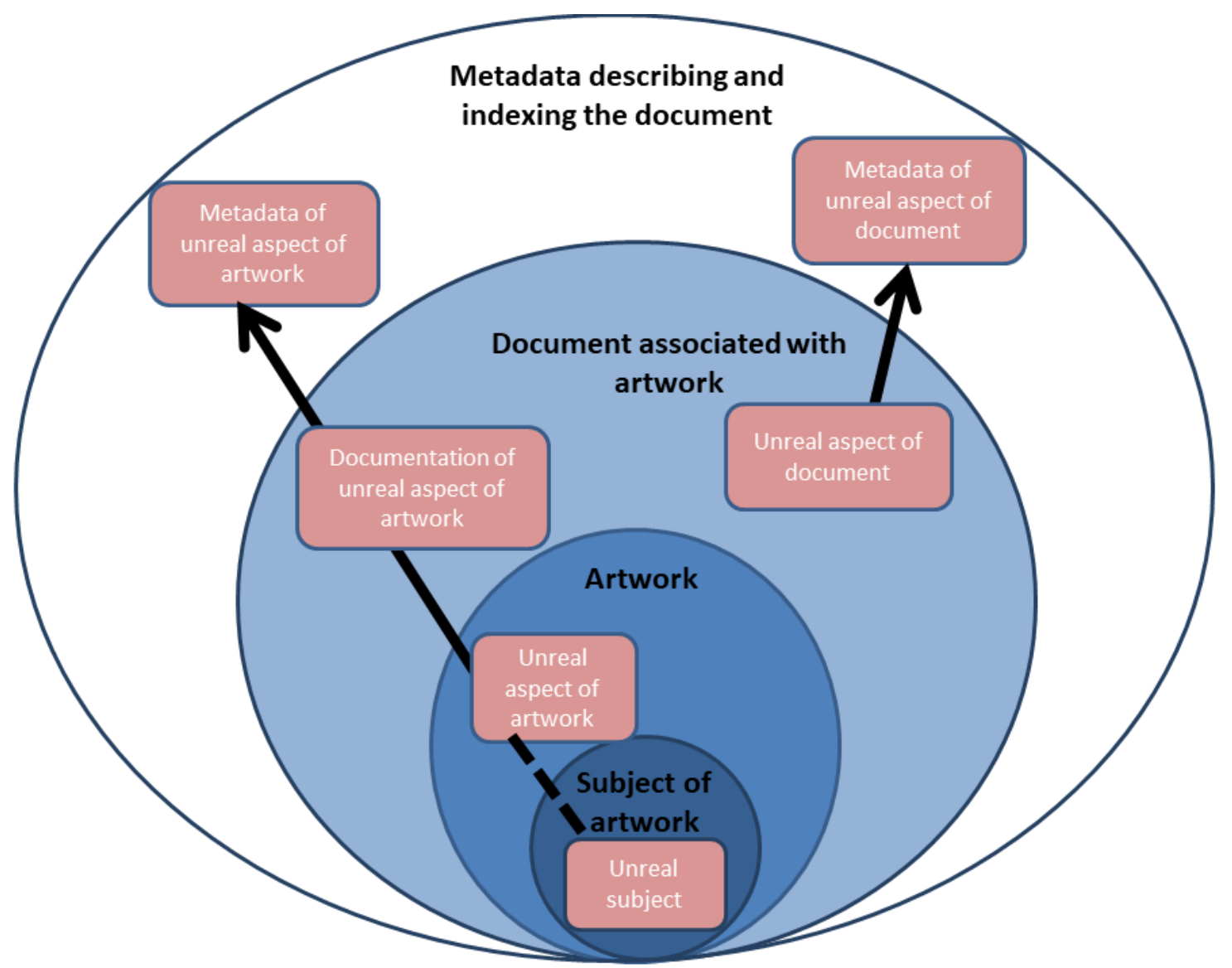


Figure 3. Model 2: Concentric circles of unreality

\subsection{Model 3: Unreal-ness as a type of information}

The artistic unreal examples demonstrate that there is an important factor for making decisions about a document's metadata: motive for unreal-ness. In other words, why is this unreal or deceptive element in the document or artwork? In the three examples of art documentation we assume that the creators' reasons for the unreal aspects are related to the experiential elements of the artworks and/or exhibition documentation. This is in contrast with, say, false memoirs, where the unreal element may be to represent the author in a better light, to increase sales, or that the author may not be able to distinguish fact from fiction, and so on. (This leads to a question which is outside the remit of this paper about whether it is possible that one person's false memoir is another person's artistic deception.)

So, unreal-ness as a category of information is visualized in Figure 4. Motive appears as one of the constituents feeding into unreal-ness. Some example classes within the category of motivation are given, such as deception for artistic purpose. As discussed, different motives for the unreal elements might lead to different practices by metadata creators. The importance and closeness of the creator to the idea of motive is illustrated. This follows on from discussions earlier in this section about how artistic unreal-ness highlights the creators' role in the ethics of KO. Another factor feeds into unrealness: transparency. The three artistic examples highlight there is a scale of the ease in locating the unreality. For example, the Heide example had explicit information about the unreal element on the actual exhibition document, whereas similar information was very difficult to find for the Bartana example. All three art documentation examples are in contrast to other types of unreal works such as false memoirs, where the transparency value would be zero. Transparency would be useful information for metadata creators when deciding whether the unreal-ness should be included in the description at all, and if so, could inform how the metadata for these elements is treated. Figure 4 illuminates possible connections between the motive for deception and the transparency. Motives 
such as improving sales or reputation are likely to correlate to low transparency; conversely, artistic purposes are visualized as linking to medium and high transparency (acknowledging that the Bartana example, which does not contain explicit statements about unreal-ness, is a counterexample to this).

The resulting unreal-ness of the document manifests itself in different aspects of the resource, which are shown as the "element which is unreal" category in Figure 4. Brubaker (2018) distinguishes between deceptions in authorial information and deceptions within the documents, so these types of information are included as classes within the "element which is unreal" category. Added to these are the classes of artwork and subject of artwork (as discussed above and seen in Figure 3). The inclusion of subject here means that, potentially, subject classification work is added to the areas of practice which are impacted by the findings in this article. A further class for exhibition highlights the divisions between an exhibition and its documentation. Again, contemplating these aspects of the resource in relation to a non-artistic example is helpful: for instance, while artwork or exhibition information would not be useful for works such as false memoirs, subject and authorial information are especially pertinent when creating metadata for false memoirs. Ultimately, Figure 4 threads together much of the previous discussion about unreal-ness, and illustrates how artistic examples show the breadth and nuance of unreal-ness and its ethical implications. 


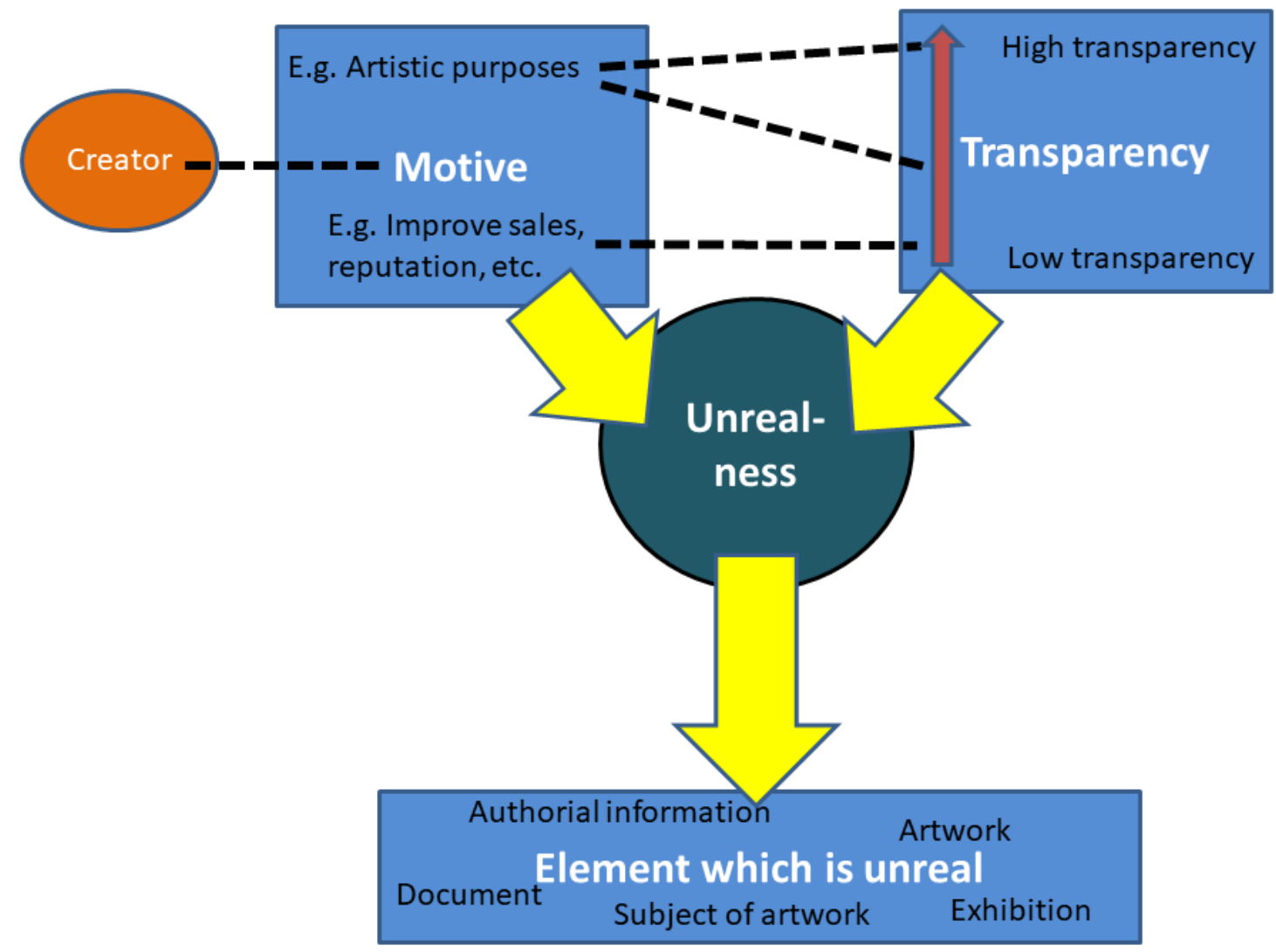

Figure 4. Model 3: Unreal-ness as a type of information

\subsection{Conclusion}

Art documentation provides specific challenges to those attempting to describe and index them in an ethical fashion. This article has used three examples of documentation relating to exhibitions, to highlight where fault lines can occur. These have illuminated differences to other types of deceptive works and presented new dimensions to the ethical issues of KO. The three examples show how for some art documentation, the documents are part of the experience of the artworks; in turn, the metadata creator then has to ponder whether to include metadata about unreal elements, if that might have an impact on the user's experience of those documents. So, the ethical needs of the documents' creators become important. Therefore, the artistic examples and Model 1 contribute to the development of discourse surrounding applied KO ethics: they add a novel ethical need, they introduce a novel set of people to add to the list of catalogers' obligations, and they add an extra 
layer to the complications of balancing different ethical principles. The examples also illuminate a hitherto unknown aspect of dealing with deceptive works: the richness of the idea of reality. Model 2 visualized the position of the unreal element in relation to the catalog record, and introduced the idea that different cataloging and indexing decisions might be made depending on the distance between the unreal element and the metadata. This is a novel aspect of considering deception and unreality in KO ethics. Model 3 posited that unreal-ness is actually a whole type of information, belonging perhaps to meta-metadata, and that this category of information is critical for cataloging and indexing any item. Furthermore, though these models germinated in the artistic unreal examples, they are potentially applicable to any document which has an element of the unreal. Therefore, considering the ethics of $\mathrm{KO}$ for art documentation expands our knowledge and understanding of applied ethics more generally.

There are a number of wider uses and implications to these findings. The importance of considering art-related works in research about ethics is clear. Therefore, it would be valuable for future work on codes of ethics to specifically consider art documentation such as the examples presented. In a similar vein, this work is also important for those developing general guidelines about art cataloging. For instance, this ethical lens would be a valuable addition to future editions of manuals which discuss cataloging exhibition documentation, such as guides by the British Library (2020) and ARLIS UK \& Ireland (2000). The discussions about unreality are potentially useful when considering the theory of the practice of metadata creation, as it brings in unreality as a new, complex aspect of information, and asks questions about what, exactly, is being described and indexed. Finally, the ideas presented in this article are also valuable when thinking about more general issues to do with the findability and display of metadata to users. For instance, while theoretically there is no way to simultaneously include a piece of information (it is not the original newspaper) and to not include it (it is the original newspaper), there is a solution from a systems perspective. The resource discovery layer or catalog could be designed to blank out specific information related to unrealities, which the user than chooses to uncover; this is akin to "spoiler sections" found in some resources about film 
and television. So, these art examples are also insightful about potential interactions between KO decisions and user experiences of catalogs, and this could have implications for future systems design.

Future research in this area could explore other creative works. It would be valuable to consider art documentation in comparison to other artistic areas such as novels, films and music. Another useful extension would be to consider the ethics of creating metadata for pastiche and parody, and whether similar issues and structures emerge to those discussed here. It would also be fascinating to link these findings to research in machine learning in bibliographic description and knowledge organization. The Bartana example showed how difficult it was for a trained human cataloger to establish whether an aspect was real or not. What does this mean for description and indexing produced by machine learning? Ultimately, considering the KO ethics of art documentation not only extends our thinking about how to deal with deception and unreality from a KO perspective, but also reframes the broader relationship between metadata creator, artistic creator and library user.

\subsection{References}

Adler, Melissa. 2016. "The Case for Taxonomic Reparations." Knowledge Organization 43: 630-9.

ARLIS NA. 2010. Cataloging Exhibition Publications: Best Practices: Name and Title Access Points.

[United States]: Art Libraries Society of North America.

https://www.arlisna.org/images/researchreports/cepbp-ntap.pdf

ARLIS UK \& Ireland. 2000. Art Exhibition Documentation in Libraries: Cataloguing Guidelines. [United Kingdom]: ARLIS UK \& Ireland. 
Armstrong, Elizabeth, D. Graham Burnett, Tom Gunning, Norman M. Klein, Carrie Lambert-Beatty, Mark Levy, and Glenn D. Lowry. 2012. More Real? Art in the Age of Truthiness. Minneapolis: Minneapolis Institute of Arts.

Artes Mundi. Artes Mundi 4. Accessed May 14, 2020. http://www.artesmundi.org/en/exhibitionsprizes/artes-mundi-four.

Bair, Sheila. 2005. "Toward a Code of Ethics for Cataloging." Technical Services Quarterly 23, no.1: 13-26.

Bartana, Yael. 2009a. The Jewish Renaissance Movement in Poland: A Manifesto [poster].

---. 2009b. Wall and Tower D.I.Y. [poster].

---. 2020. And Europe Will Be Stunned / Mur i Wieża (Wall and Tower), 2009. Accessed May 14, 2020. http://yaelbartana.com/project/sirens-song-2005\#info.

British Library. 2020. Special Topics in RDA: Exhibition and Art Catalogues. [United Kingdom]: British Library. Accessed May 14, 2020. https://www.bl.uk/bibliographic/pdfs/rda-exhibitions-and-artcatalogs-201412.pdf.

Brubaker, Jana. 2018. Text, Lies and Cataloging: Ethical Treatment of Deceptive Works in the Library. Jefferson, North Carolina: McFarland \& Company.

Cataloging Ethics Steering Committee. 2020a. Cataloging Ethics Steering Committee Website. Accessed September 17, 2020. https://sites.google.com/view/cataloging-ethics/home.

-- -. 2020b. Draft Cataloguing Code of Ethics (Revised Sept. 2020). Accessed September 17, 2020. https://docs.google.com/document/d/1tnTetySv6mgCa4RfScaffykQdtViZZ8M5nwgowZboQk/e dit 
Cembalest, Robin. 2013. "Let My People Go -- Back to Poland." Artnews. April 18, 2013.

https://www.artnews.com/art-news/news/yael-bartana-jewish-renaissance-movement-2214/.

"Deceive, v., 2a." 1989. OED online. 2nd ed. https://www.oed.com/view/Entry/48096

Dibert, Randall R. 1980. “The Composer's Intentions: An Examination of Their Relevance for Performance." The Musical Quarterly 66: 205-218. https://www.jstor.org/stable/742088

Ferrari, Roberto C. 2000. "The Art of Classification: Alternate Classification Systems in Art Libraries." Cataloging and Classification Quarterly 28, no. 2: 73-98. https://doi.org/10.1300/J104v28n02_07

“Fiction, n., 4a." 1989. OED online. 2nd ed. https://www.oed.com/view/Entry/69828

Fox, Melodie J. 2014. “Medical Discourse's Epistemic Influence on Gender Classification in Three Editions of the Dewey Decimal Classification." In Knowledge Organization in the 21st Century: Between Historical Patterns and Future Prospects: Proceedings of the $13^{\text {th }}$ International ISKO Conference 19-22 July 2014 Krakow, Poland, edited by Wiesław Babik. Würzburg: Ergon Verlag, 228-235.

Fox, Melodie J. and Austin Reece. 2012. "Which Ethics? Whose Morality?: An Analysis of Ethical Standards for Information Organization." Knowledge Organization 39: 377-83.

Fox, Violet and Kelly Swickard. 2018. “My Zine is my Private Life: Reframing Authority Control from Detective Work to an Ethic of Care." In Ethical Questions in Name Authority Control, edited by Jane Sandberg. Sacramento: Library Juice Press, 9-23.

Galeffi, Agnese, María Violeta Bertolini, Robert L. Bothmann, Elena Escolano Rodríguez and Dorothy McGarry. 2017. Statement of International Cataloguing Principles (ICP). [2016 edition with 
minor corrections]. Den Haag: IFLA.

https://www.ifla.org/files/assets/cataloguing/icp/icp_2016-en.pdf.

Grandal Montero, Gustavo. 2017. "Art Documentation: Exhibition Catalogues and Beyond". In The Handbook of Art and Design Librarianship. $2^{\text {nd }}$ ed., edited by Paul Glassman and Judi Dyki. London: Facet, 109-117.

Heide, Sara van der, Anselm Franke, Kyungman Kim and Gabriele Stötzer. 2016. Sara van der Heide: Die Deutsche Informations-Bibliothek Pjöngjang. Berlin: Sternberg.

Heyl, Bernard C. 1950. "'Artistic Truth' Reconsidered." The Journal of Aesthetics and Art Criticism 8: 251-258.

Homan, Philip A. 2012. "Library Catalog Notes for "Bad Books": Ethics vs. Responsibilities." Knowledge Organization 39: 347-55.

Lee, Deborah. 2011. "Dealing with Adaptation: the Courtauld classification scheme." Art Libraries Journal 36: 26-33.

Library of Congress. 2020a. "MARC21 Format for Authority Data". https://www.loc.gov/marc/authority/

-- . 2020b. "MARC21 Format for Bibliographic Data”. https://www.loc.gov/marc/bibliographic/

Olson, Hope A. 2007. "How we Construct Subjects: A Feminist Analysis." Library Trends 56: 509-41.

“Movement, $n .$, 8a" 2003. OED online. 3rd ed. https://www.oed.com/view/Entry/123031

Price, Kingsley Blake. 1949. “Is There Artistic Truth?” The Journal of Philosophy 46(10), 285-291.

The Pyongyang Times. 2016. 9 April (No. 15, 2894). 
Random Institute. 2016. The Pyongyang Times. Vienna: Mark Pezinger.

- - All the Lights we Cannot See. Accessed May 14, 2020.

https://randominstitute.org/event/north-korea-show.

"RDA Toolkit." Accessed May 14, 2020. https://www.rdatoolkit.org/.

Shoemaker, Elizabeth. 2015. "No one Can Whistle a Symphony: Seeking a Catalogers' Code of Ethics." Knowledge Organization 42: 353-7.

Slager, Henk. 2016. "Timely meditations." In Sara van der Heide, Anselm Franke, Kyungman Kim and Gabriele Stötzer. Sara van der Heide: Die Deutsche Informations-Bibliothek Pjöngjang. Berlin: Sternberg, [Exhibition catalog] 3.

Snow, Karen. 2015. "An Examination of the Practical and Ethical Issues Surrounding False Memoirs in Cataloging Practice." Cataloging \& Classification Quarterly 53: 927-47.

Starnes, Sadie. 2016. “No-place: A clandestine Exhibition in North Korea." Artcritical, June 9, 2016.

Sun, Jong Hwa. 2016. "Pump factory focussed on technological development." Pyongyang Times, 9 April (No. 15, 2894).

"Unreal, adj. (and int.) and n., 1." 2014. OED online. $3^{\text {rd }}$ ed. http://www.oed.com/view/Entry/216842

XXXXX catalog. Details removed to protect author anonymity. 